\title{
Simpson Grade 4
}

National Cancer Institute

\section{Source}

National Cancer Institute. Simpson Grade 4. NCI Thesaurus. Code C128620.

Partial removal, leaving the intradural tumor in situ. 